Gut, 1982, 23, 984-991

\title{
Clinical experience of zinc supplementation during intravenous nutrition in Crohn's disease: value of serum and urine zinc measurements
}

\author{
A N H MAIN, M J HALL, R I RUSSELL, ${ }^{*}$ G S FELL, P R MILLS, and A SHENKIN \\ From the Gastroenterology Unit and Department of Biochemistry, Royal Infirmary, Glasgow
}

SUMMARY Serum zinc concentrations and urine zinc excretion have been studied in 10 patients with severe Crohn's disease before and during 59 patient-weeks of intravenous nutrition. Before serum zinc concentrations $(9.9 \pm 1.0 \mu \mathrm{mol} / \mathrm{l}$ : mean $\pm \mathrm{SEM})$ and urine zinc excretion $(3.3 \pm 0.6$ $\mu \mathrm{mol} / 24 \mathrm{~h})$ were less than controls $(\mathrm{p}<0 \cdot 01)$. No patients had clinical signs of zinc deficiency before intravenous nutrition and none developed signs during it. There was no overall change in serum zinc concentrations, despite improvements in body weight, skinfold thickness, and mid-arm circumference in all patients, and increased serum albumin and serum transferrin concentrations during all but two periods of intravenous nutrition. Nor was there any relationship between serum zinc concentrations and zinc intake (up to $220 \mu \mathrm{mol} / \mathrm{day}$ ), serum zinc concentrations remaining significantly lower than control levels. Urine zinc excretion during the first week of intravenous nutrition showed a 1.2 to 53 -fold increase (mean 11-fold) over pre-intravenous nutrition levels, and a positive relationship was demonstrated between zinc intake and urine zinc excretion. It is suggested that zinc supplied by the intravenous route is inefficiently transported to the tissues, and that some is excreted in the form of small molecular weight chelates into urine. Recommendations are made for the supply of intravenous zinc, based on monitoring urine zinc excretion in individual patients.

Zinc is an essential element in man and is required for the function of over 70 metallo-enzymes. ${ }^{1}$ Clinical manifestations of zinc deficiency include acrodermatitis, hair loss, hypogonadism, growth retardation, delayed wound healing, and impaired immune competence. ${ }^{2-5}$

Zinc deficiency has been described in Crohn's disease ${ }^{67}$ the causes including low intake, poor absorption, ${ }^{8}$ and excess faecal losses. ${ }^{9}$ Intravenous nutrition can be complicated by the development of zinc deficiency. ${ }^{10-13}$ Some patients with extensive Crohn's disease may need intravenous nutrition ${ }^{14}$ and zinc deficiency may occur, especially when patients become anabolic. ${ }^{10}{ }^{15} \mathrm{Zinc}$ is thus an important component of the intravenous diet but daily requirements are not certain, as they will vary according to zinc losses principally in faeces and

* Address for correspondence: Dr R I Russell, Gastroenterology Unit, Royal Infirmary, Glasgow G4 0SF.

Received for publication 6 March 1982 urine, and also in fistula fluid, wound exudates, shed skin and hair.

Determination of zinc in serum and urine is, however, readily available as part of the biochemical monitoring of patients receiving intravenous nutrition. As we have used a wide range of intravenous zinc supplements in our patients, we have sought to relate the results of such zinc measurements to the quantity of zinc given, to clinical progress, and nutritional indices. Serum and urine zinc values are considered in relation to serum protein changes, body weight, skinfold thickness and muscle circumference, and an estimate of nitrogen balance.

\section{Methods}

PATIENTS

Ten patients with Crohn's disease requiring intravenous nutrition were studied, comprising six women and four men of mean age 28.5 years. Clinical details including the extent of disease, 
previous surgery, drug therapy, and reasons for intravenous nutrition, as well as baseline anthropometric and biochemical data, are shown in Table 1. Body weight standard, and reference values for triceps skinfold thickness and mid-arm circumference were based on WHO Tables. ${ }^{16}$ These 10 patients underwent 14 periods of intravenous nutrition of mean duration five weeks for a total of 64 complete weeks (Table 2). Because of occasional breakages and urine contamination, serum values are available for only 57 weeks and urine values for 59 weeks.

Intravenous nutrition was administered by a cannula inserted into a central vein. All patients received sufficient nitrogen in the form of an amino acid solution (Synthamin: Travenol Laboratories) to maintain a positive nitrogen balance as judged from 24-hour urine nitrogen excretion, which was measured twice weekly with a faecal allowance as indicated in Table 2 . The nitrogen input ranged from 9-17 $\mathrm{g}$ per day. Energy was supplied in the form of glucose (10-50\%) and fat emulsion (10 and $20 \%$ Intralipid: KabiVitrum) to maintain the calorie to nitrogen ratio between 150 and 250 to 1 : $(0 \cdot 16-0.33 \mathrm{MJ} / \mathrm{kg} /$ day $(39-80 \mathrm{kcal} / \mathrm{kg} /$ day $))$. Other additions were electrolytes $\left(\mathrm{Na}, \mathrm{K}, \mathrm{Ca}, \mathrm{Mg}, \mathrm{PO}_{4}\right)$, fat-soluble and water-soluble vitamins including folic acid (Vitlipid, Solivito: KabiVitrum), and a trace metal solution (Addamel: KabiVitrum) which contains $5 \mathrm{mmol} \mathrm{Ca}{ }^{++}, 1.5 \mathrm{mmol} \mathrm{Mg}{ }^{++}, 50 \mu \mathrm{mol}$ $\mathrm{Fe}^{+++}, 20 \mu \mathrm{mol} \mathrm{Zn}{ }^{++}, 40 \mu \mathrm{mol} \mathrm{Mn}{ }^{++}$, and $5 \mu \mathrm{mol}$ $\mathrm{Cu}^{++}$per vial. Additional zinc was supplied as zinc sulphate solution containing $100 \mu \mathrm{mol}(6.5 \mathrm{mg})$ zinc/vial. No patients received oral zinc supplements.

Patients were examined throughout for clinical signs of zinc deficiency such as hair loss and acrodermatitis.

Estimations of zinc in serum and urine by flame atomic spectrophotometry were performed throughout by the method of Peaston. ${ }^{17}$ Patients taking oral food were fasted overnight and all serum samples were taken early in the morning. Urine was collected in stainless steel urinals and transferred to cleaned plastic bottles for estimations of 24-hour zinc excretion, as papier-mâché disposable bottles seriously contaminate urine with zinc and other metals. Assessment of serum and urine zinc status was made in the Crohn's patients before intravenous nutrition and twice a week during it. The average weekly value was calculated. Daily intravenous zinc intake was determined for each patient-week of feeding.

Control groups consisted of 36 healthy patients fasting before minor orthopaedic surgery (serum values) and 12 healthy volunteers (urine values).
Serum albumin and serum zinc levels were also compared in the following groups: (1) 50 fasting hospitalised patients about to undergo minor orthopaedic surgery (controls); (2) 21 hospitalised patients with active inflammatory bowel disease (inflammatory bowel disease group); (3) in all 10 Crohn's patients throughout their periods of intravenous nutrition (intravenous nutrition group).

Statistical comparisons between groups were by a Mann Whitney test, but, in addition, mean values and standard errors of the mean are quoted. Relationships between serum albumin and serum zinc were examined by linear regression.

\section{Results}

PRE-INTRAVENOUS NUTRITION STATUS (Table 1) All but two patients were $80 \%$ or less of standard weight for height. Patient number 5, whose nutritional state was normal, was fed intravenously to allow bowel rest for the relief of severe rectal symptoms. The skinfold thickness and mid-arm muscle circumference were low in most patients.

Serum zinc values (mean $\pm \mathrm{SEM} \mu \mathrm{mol} / \mathrm{l}$ ) in the 10 Crohn's patients $(9.9 \pm 1 \cdot 0)$ were less than in the 36 controls $(13.2 \pm 0.3 ; \mathrm{p}<0.01)$. Urine values (mean \pm SEM $\mu \mathrm{mol} / 24 \mathrm{~h}$ ) for eight of the Crohn's group $(3.3 \pm 0.6)$ were less than in 12 controls $(7 \cdot 0 \pm 0 \cdot 8 ; p<0 \cdot 01)$. No patients had clinical signs of zinc deficiency.

PROGRESS ON INTRAVENOUS NUTRITION (Table 2) The nutritional state of all patients improved with increases in body weight, skinfold thickness, and mid-arm circumference. This was accompanied by positive nitrogen balance and increases in serum transferrin concentrations in most patients. Increases in serum albumin concentrations occurred during 12 of the 14 periods of intravenous nutrition. Patients 2 and 4 received intravenous protein or blood during intravenous nutrition.

Severe diarrhoea, likely to increase zinc loss, occurred in patients $2,4,8$, and 10 . Systemic sepsis occurred only in patient 3 . Minor local sepsis related to the intravenous cannula occurred in several patients and was readily corrected by its replacement. The only major complication of intravenous nutrition was in patient 8 who developed superior vena cava obstruction which necessitated stopping this form of nutrition.

\section{SERUM ZINC LEVELS}

The improvement in nutritional state in all patients was not accompanied by a predictable overall change in serum zinc levels, which increased during nine periods of intravenous nutrition and decreased 


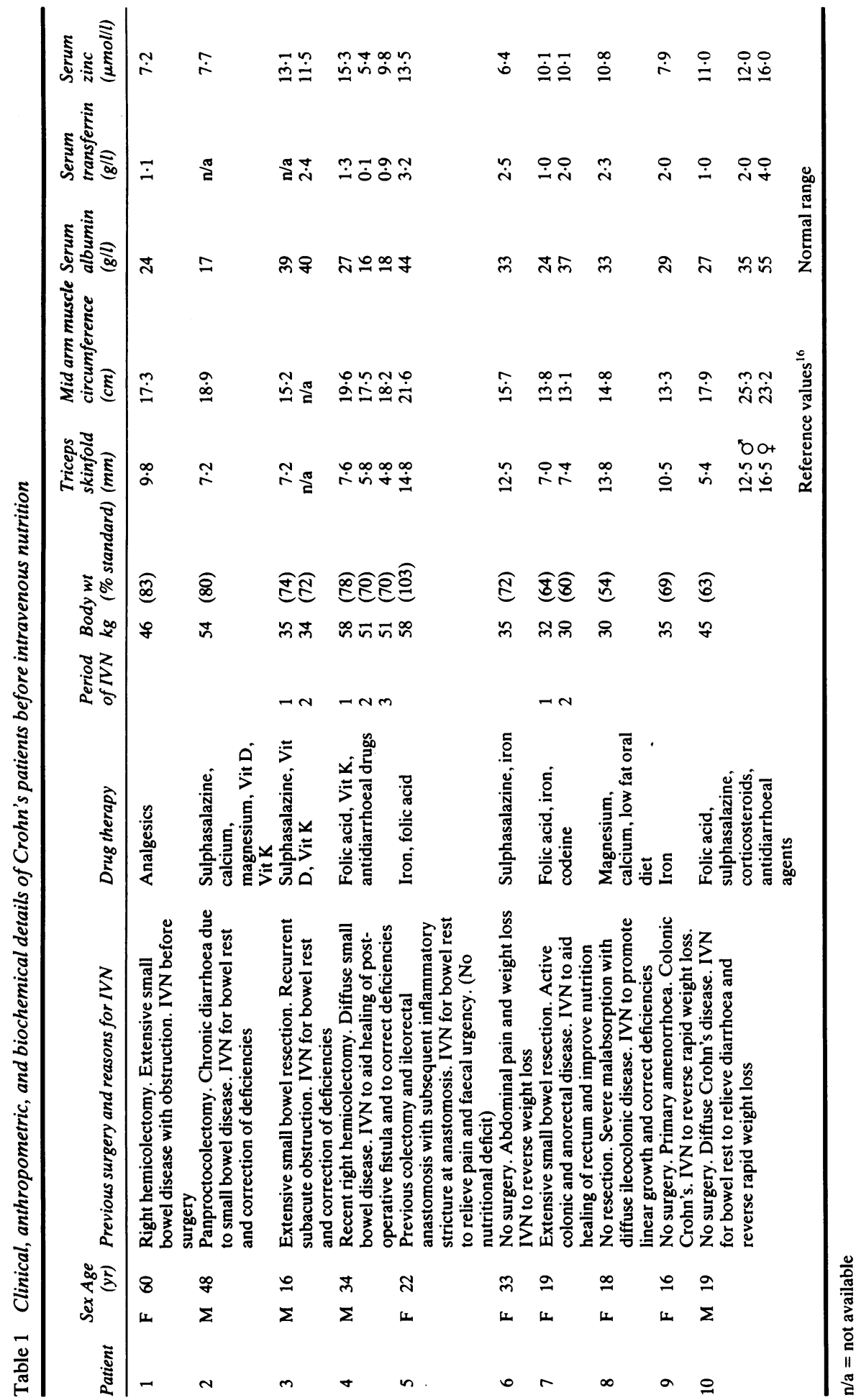




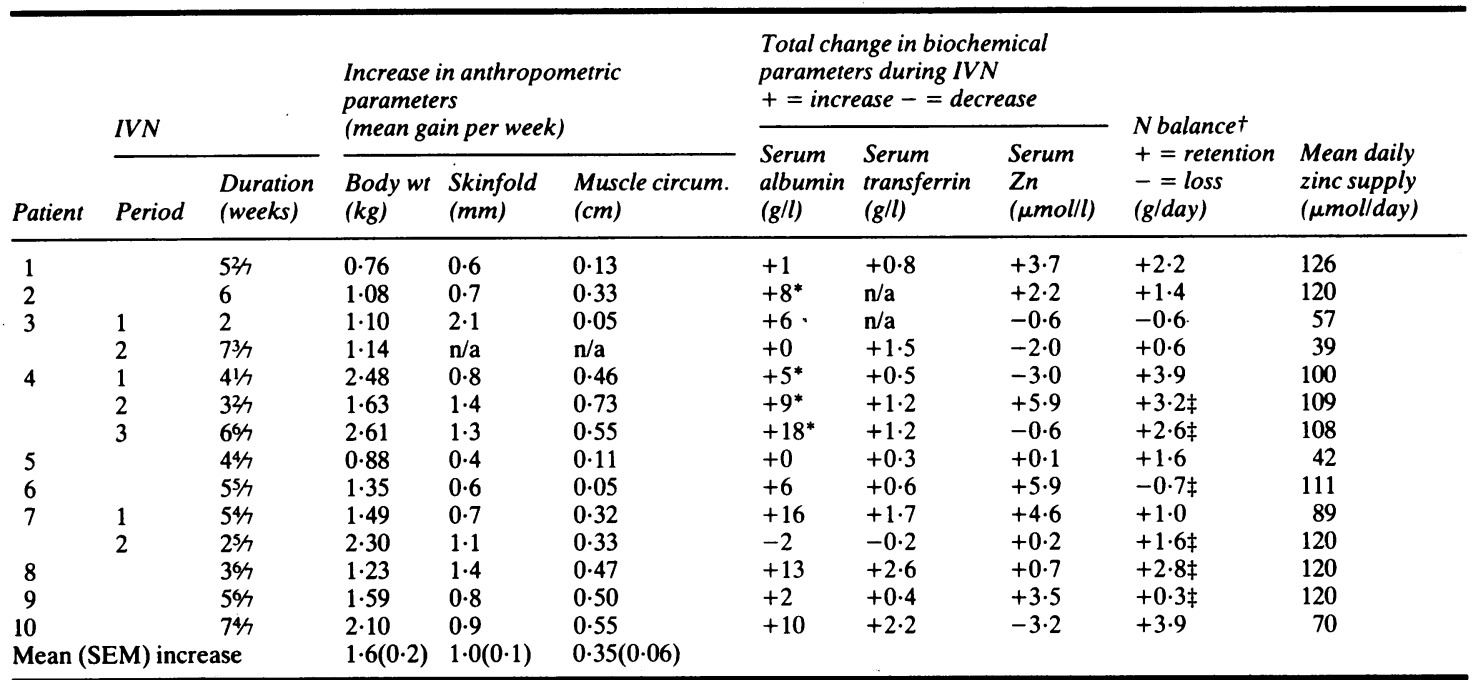

† An estimate from known iv intake, urine output, and an arbitrary faecal excretion allowance of $2 \mathrm{~g} /$ day.

¥ Small additional quantities of oral food given.

* IV blood or protein administered during IVN.

n/a: not available.

during the remaining five periods (Table 2). Serum zinc levels in patients with diarrhoea (nos $2,4,8,10$ ) were not different from those without diarrhoea. There was no relationship between the mean daily zinc supply and the overall changes in serum zinc concentration. Nor had the level of zinc supply an influence on serum zinc concentrations (Fig. 1). The

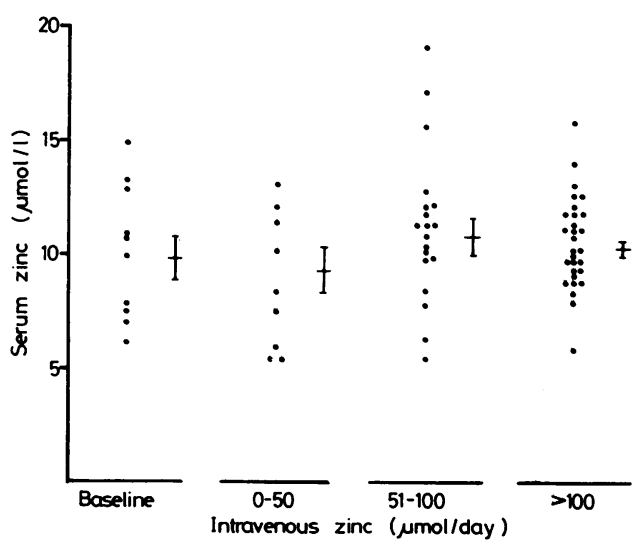

Fig. 1 Serum zinc concentrations before intravenous nutrition (baseline) and during each of 59 patient-weeks of intravenous nutrition, separated according to the quantity of zinc supplied. Bars indicate the mean and standard error for each group. serum zinc concentrations (mean $\pm \mathrm{SEM} \mu \mathrm{mol} / \mathrm{l}$ ) in the low intake group $(9 \cdot 4 \pm 1 \cdot 0)$ and the two higher zinc intake groups $(11 \cdot 0 \pm 0 \cdot 8 ; 10 \cdot 5 \pm 0.4)$ were not significantly different from baseline values, and were less than controls ( $p<0.01$ for each group). No patient received more than $220 \mu \mathrm{mol}$ of zinc per day.

Patient 10 , whose period of intravenous nutrition is illustrated in Fig. 2, was the only patient to exhibit a fall in serum zinc concentration (13.0 to 7.8 $\mu \mathrm{mol} / \mathrm{l})$ after his serum proteins had risen and his body weight increased $8 \mathrm{~kg}$ in only two weeks. His zinc intake was $70 \mu \mathrm{mol} /$ day.

The relationship between serum albumin and serum zinc is shown in Table 3. Serum albumin was lower in the inflammatory bowel disease group $(p<0.001)$ and intravenous nutrition $(p<0.001)$ group than in controls. Serum zinc, similarly, was lower in the inflammatory bowel disease $(p<0.001)$ and intravenous nutrion $(p<0 \cdot 001)$ groups than in controls. There was a significant correlation between serum albumin and serum zinc only in the combined group and in the inflammatory bowel disease group.

\section{URINE ZINC EXCRETION}

As illustrated in Fig. 3, all levels of intravenous zinc supply were associated with a rise in urine zinc excretion above baseline values. The differences between each of the intake groups and the baseline 


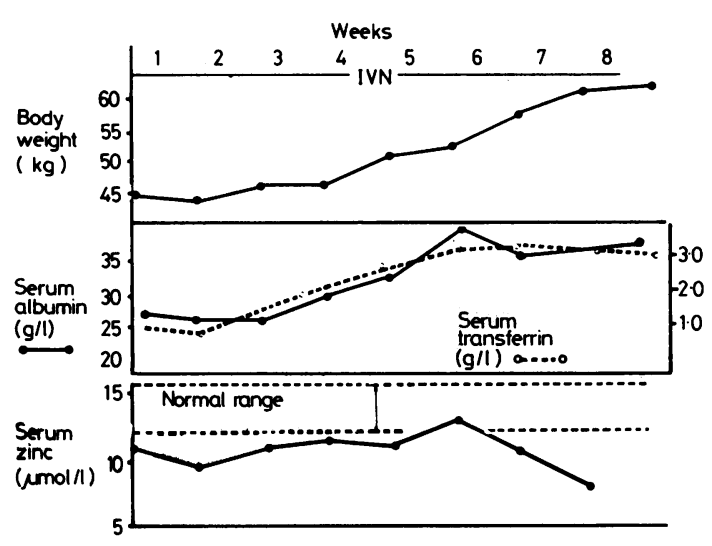

Fig. 2 Intravenous nutrition in patient 10.

values were significant. Urine zinc excretion in the two highest groups was greater than when the zinc supply was less than $50 \mu \mathrm{mol} / \mathrm{day}(\mathrm{p}<0.005$; $p<0.01)$. When urine zinc excretion was expressed as a percentage of intake for each intake group (Table 4), however, there was no difference in the mean percentage of intake excreted between the intake groups, a wide range being present in each group. Low urine zinc excretion (mean \pm SEM) $(3.3 \pm 0.06 \mu \mathrm{mol} / 24 \mathrm{~h})$ was observed before intravenous nutrition. During the first week of feeding a rise in urine output was observed in all patients varying from a 1.3 to a 53 -fold increase, the mean increase being 11 times the value before intravenous nutrition. In one patient, urine zinc losses diminished markedly after albumin $(93 \mathrm{~g})$ was given intravenously during the second week of intravenous nutrition (Fig. 4), while serum zinc levels remained low $(<10 \mu \mathrm{mol} / \mathrm{l})$ throughout. Patient 2 showed a similar drop in urine zinc output (158 to $18 \mu \mathrm{mol} / 24 \mathrm{~h}$ ) after a transfusion of blood

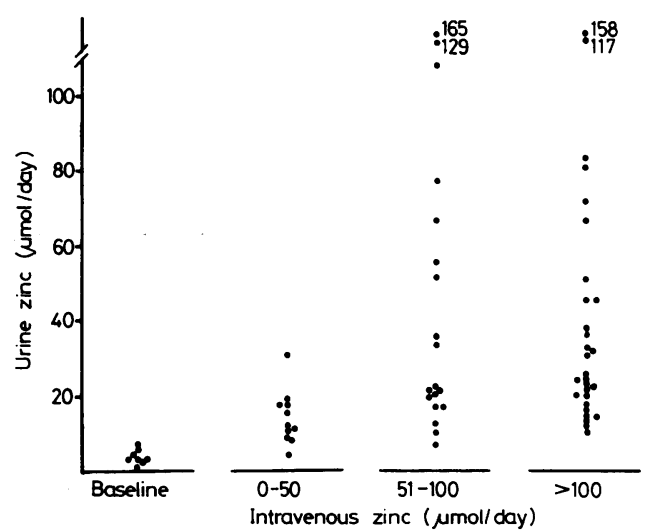

Fig. 3 Daily urine zinc excretion before intravenous nutrition (baseline) and during each of 59 patient-weeks of intravenous nutrition separated according to zinc supply.

was given. No other patients received protein during intravenous feeding.

\section{Discussion}

\section{SERUM ZINC VALUES}

This study has demonstrated low serum zinc levels in severe Crohn's disease and confirms the findings of other workers. ${ }^{6-8}$ Despite nutritional improvement in all patients, low serum zinc levels were not changed during intravenous nutrition despite zinc supply up to $220 \mu \mathrm{mol} /$ day. Fleming and colleagues $^{18}$ suggested that persistently low serum zinc concentrations during intravenous nutrition in the absence of disease associated with hypozincaemia might indicate zinc deficiency. The three patients they described, however, did have conditions which might be associated with depression of serum zinc concentration (abscess, alcoholism with pancreatitis, short bowel syndrome). We believe, however, that the only

Table 3 Relationship between serum albumin and serum zinc

\begin{tabular}{|c|c|c|c|c|c|c|c|}
\hline & \multirow{2}{*}{$\begin{array}{l}\text { Number of } \\
\text { values }\end{array}$} & \multicolumn{2}{|c|}{ Serum albumin $(g / l)$} & \multicolumn{2}{|c|}{ Serum zinc $(\mu \mathrm{mol} / \mathrm{l})$} & \multicolumn{2}{|c|}{$\begin{array}{l}\text { Correlation between } \\
\text { serum albumin and serum zinc }\end{array}$} \\
\hline & & Mean & $S E M$ & Mean & $S E M$ & $r$ & $p$ \\
\hline Controls & 50 & $43 \cdot 1$ & 0.5 & $13 \cdot 8$ & 0.3 & +0.22 & NS \\
\hline IBD* & 21 & $27 \cdot 4$ & $1 \cdot 6$ & $9 \cdot 6$ & 0.7 & +0.48 & $<0.05$ \\
\hline IVN $†$ & 57 & $31 \cdot 1$ & 0.9 & $10 \cdot 8$ & 0.3 & +0.20 & NS \\
\hline
\end{tabular}

* Inflammatory bowel disease group.

$\dagger$ Intravenous nutrition group. 
Table 4 Urine zinc excretion expressed as a \% of intravenous intake

\begin{tabular}{|c|c|c|c|}
\hline \multirow{2}{*}{$\begin{array}{l}\text { Intravenous } \\
\text { zinc intake } \\
\text { ( } \mu \text { mol/day) }\end{array}$} & \multicolumn{3}{|c|}{$\begin{array}{l}\text { Urinary zinc excretion } \\
\text { (\% of intake) }\end{array}$} \\
\hline & Mean & $S D^{*}$ & Range \\
\hline $0-50$ & 38 & 23 & $19-85$ \\
\hline $51-100$ & 54 & 48 & $14-165$ \\
\hline $101-220$ & 33 & 30 & $9-132$ \\
\hline
\end{tabular}

* Standard deviation.

proof of zinc deficiency is the emergence of clinical signs rapidly corrected by supplying zinc alone. Serum zinc levels do not give a direct guide to intracellular zinc content, ${ }^{19}$ and serum zinc levels can be moderately depressed by a variety of factors unrelated to tissue depletion.

Zinc in serum bound to $\alpha-2$ macroglobulin does not appear to be exchangeable ${ }^{8}$ and albumin is the principal zinc transporting protein. Increased production of ACTH or administration of high dose corticosteroids lowers the albumin-bound zinc fraction, ${ }^{20} 21$ as does altered pituitary activity in stress and infection. ${ }^{22}$ These factors may be partly responsible for depressed plasma zinc levels in Crohn's disease. That hormonal influences probably play a part in regulating serum zinc levels is suggested by the diurnal rhythm in normal subjects. ${ }^{23}$ Leucocyte endogenous mediator lowers total plasma zinc levels in infection ${ }^{22}$ and in Crohn's disease. ${ }^{24}$

It has been suggested that low serum zinc in Crohn's disease simply reflects reduction in serum

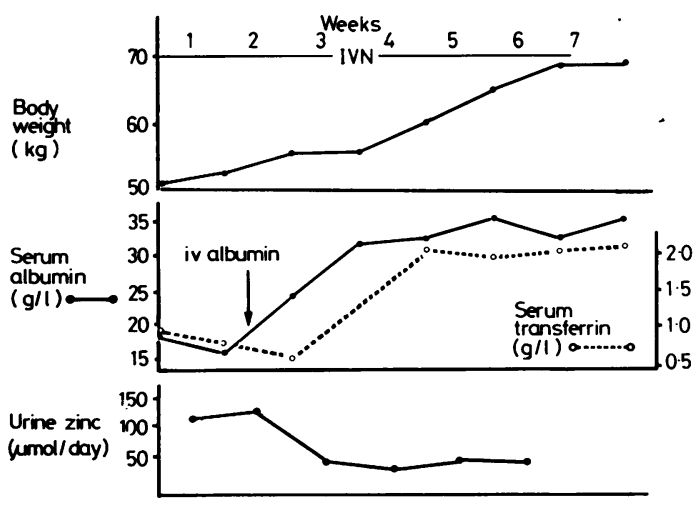

Fig. 4 The third period of intravenous nutrition in patient 4: weight gain during the first two weeks of intravenous nutrition was attributable to the accumulation of oedema fluid which rapidly disappeared after the infusion of $93 \mathrm{~g}$ albumin during the second week of intravenous nutrition. albumin. ${ }^{8}$ This view is not entirely supported by our data. Although there was a good correlation between serum albumin and serum zinc in our combined group, this did not hold true for the patients receiving intravenous nutrition and serum albumin levels tended to rise during the course of this form of feeding while zinc levels did not. Wolman and colleagues were able to show a positive relationship between plasma zinc and the amount of zinc infused during intravenous nutrition. ${ }^{9}$ They infused zinc in quantities up to almost $400 \mu \mathrm{mol} /$ day. Their patients with diarrhoea achieved positive zinc balance with $185 \mu \mathrm{mol}$ of zinc (12 mg) daily. Our patients with severe diarrhoea (nos $2,4,8$, and 10) received less than this (Table 2 ) and it is possible that a positive relationship between zinc supply and plasma zinc would have been achieved by increasing zinc supply in these patients. In patient 10 serum zinc level fell during a period of rapid anabolism. This single observation clearly needs further documentation, but Kay and his colleagues ${ }^{15}$ considered anabolism in the absence of adequate zinc supply to be responsible for profound falls in plasma zinc levels to less than $5 \mu \mathrm{mol}$ zinc/l preceding clinical signs of zinc deficiency.

\section{URINE ZINC EXCRETION}

In this study low urine zinc levels were found in severe Crohn's disease in contrast with our previous report. ${ }^{25}$ Low urine zinc has been considered to reflect tissue zinc depletion, ${ }^{26}$ but may also be due to raised levels of LEM as this substance, released from white blood cells, stimulates liver uptake of amino acids ${ }^{27}$ and might lower the ultrafilterable amino acid-bound zinc fraction and therefore the amount of zinc available for urinary excretion.

There may be inefficient retention of zinc supplied by the intravenous route. When the three intake groups were compared we found a relationship between intravenous zinc supply and urine zinc excretion but there was wide variation in the proportion of infused zinc excreted in urine within each of the intake groups and during the course of intravenous nutrition in individual patients. We also observed a rapid increase in urine zinc excretion during the first week of intravenous nutrition. These findings might be explained by a difference in chelation of zinc with other nutrients in the premixed feed and differing availability of zinc binding sites in plasma. Increasing the serum zinc ultrafilterable fraction would result in urinary losses. Van $\mathrm{Rij}$ and his colleagues ${ }^{28}$ showed a six-fold increase in urine zinc excretion when amino acids and zinc were given intravenously. Freeman ${ }^{29}$ attributed a similar rise in urine zinc excretion to the formation of amino sugar-zinc complexes. 
Reduction in urine zinc excretion was seen in two patients who received plasma proteins intravenously during intravenous nutrition. This suggests that the retention of intravenous zinc may be improved by increasing zinc binding proteins, principally albumin, thereby perhaps reducing the ultrafilterable zinc fraction.

CONCLUDING REMARKS AND RECOMMENDATIONS While serum and urine zinc measurements are poor indicators of tissue zinc status, they are, in clinical practice, the means by which judgements are made about the adequacy of zinc supplementation during intravenous nutrition. In the present study, serum zinc concentrations remained low throughout intravenous feeding despite substantial increases in serum albumin in several patients, and serum zinc levels gave no guide to zinc requirements. As a general rule we have found that the provision of 100 $\mu \mathrm{mol}(6 \mathrm{mg})$ of zinc/day is adequate to prevent the syndrome of zinc deficiency during intravenous nutrition. The variability of zinc excretion during intravenous nutrition makes firm recommendations about additional zinc supply difficult. Nonetheless, monitoring of urine zinc excretion may help in the management of individual patients. Low urine zinc excretion before intravenous nutrition $(<2 \mu \mathrm{mol}$ zinc/day) can be expected when the patient is zinc depleted but not catabolic. During intravenous nutrition low excretion can be expected when blood or albumin is given. We suggest that 24 hour urine zinc excretion should be measured several times during the first two weeks of intravenous nutrition. If urinary zinc excretion is persistently high $(>80$ $\mu \mathrm{mol} / \mathrm{day}$ ) or even exceeds input, the clinician should suspect either catabolism or poorly utilised zinc supply. In these circumstances, it might be reasonable to increase zinc supply to $200 \mu \mathrm{mol} / \mathrm{day}$, especially if the patient subsequently becomes anabolic. More specific advice depends on the use of carefully controlled balance studies or better markers of whole-body zinc status.

Mechanisms of zinc absorption from the gut are complex and incompletely understood, ${ }^{30}$ but oral supplementation of zinc has been used effectively in zinc deficiency occurring during intravenous nutrition. ${ }^{10}$ It might be less appropriate in patients with Crohn's disease and severe diarrhoea.

\section{References}

1 Riordan JF. Biochemistry of zinc. Med Clin North Am 1976; 60: 661-74.

2 Ecker RI. Acrodermatitis and acquired zinc deficiency.
Arch Dermatol 1978; 114: 937-9.

3 Halsted JA, Ronaghy HA, Abadi P. Zinc deficiency in man. The Shiraz experiment. Am J Med 1972; 53: 277-84.

4 Wacker WEC. Role of zinc in wou. healing: a critical review. In: Prasad AS, ed. Trace elements in human health and disease. Vol 1. New York: Academic Press, 1976: 107-13.

5 Golden MHN, Golden BE, Harland PSEG, Jackson AA. Zinc and immuno competence in protein-energy malnutrition. Lancet 1978; 1: 1226-8.

6 Solomons NW, Rosenberg IH, Sandstead HH, VoKhactu KP. Zinc deficiency in Crohn's disease. Digestion 1977; 16: 87-95.

7 McClain C, Soutor C, Zieve L. Zinc deficiency: a complication of Crohn's disease. Gastroenterology 1980; 78: 272-9.

8 Sturniolo GC, Moloklia MM, Shields R, Turnberg LA. Zinc absorption in Crohn's disease. Gut 1980; 21: 387-91.

9 Wolman SL, Anderson GH, Marliss EB, Jeejeebhoy KN. Zinc in total parenteral nutrition: requirements and metabolic effects. Gastroenterology 1979; 76: 458-67.

10 McClain CJ, Soutor C, Steele N, Levine AS, Silvis SE. Severe zinc deficiency presenting with acrodermatitis during hyperalimentation: diagnosis, pathogenesis and treatment. J Clin Gastroenterol 1980; 2: 125-31.

11 Arawaka T, Tamura T, Igareshi Y. Zinc deficiency in two infants during total parenteral alimentation for diarrhoea. Am J Clin Nutr 1976; 29: 197-204.

12 Solomons NW, Layden TJ, Rosenberg IH, Vo-Khactu K, Sandstead HH. Plasma trace metals during total parenteral alimentation. Gastroenterology 1976; 70: 1022-5.

13 Greene HL. Vitamins and trace elements. In: Chadimi $\mathrm{H}$, ed. Total parenteral nutrition: promises and premises. J Wiley, 1975; 351-71.

14 Driscoll RH, Rosenberg IH. Total parenteral nutrition in inflammatory bowel disease. Med Clin North Am 1978; 62: 185-201.

15 Kay RG, Tasman-Jones C, Pybus J, Whiting R, Black $\mathrm{H}$. A syndrome of acute zinc deficiency during total parenteral alimentation in man. Ann Surg 1976; 183: 331-40.

16 Jelliffe DB. The assessment of the nutritional status of the community. Monograph No 53. Geneva: WHO, 1966.

17 Peaston RT. The determination of zinc and copper in plasma and urine. Med Lab Technol 1973; 30: 249-53.

18 Fleming CR, Hodges RE, Hurley LS. A prospective study of serum copper and zinc levels in patients receiving total parenteral nutrition. Am J Clin Nutr 1976; 29: 70-7.

19 Golden MHN, Golden BE. Trace elements. Potential importance in human nutrition with particular reference to zinc and vanadium. Med Bull 1981; 37: 31-6.

20 Flynn A, Pories WJ, Strain WH, Hill OA, Fratianne RB. Rapid serum-zinc depletion associated with corticosteroid therapy. Lancet 1971; 2: 1169-72.

21 Falchuck KH. The effect of acute disease and ACTH 
on serum zinc proteins. $N$ Engl $J$ Med 1977; 296: 1129-34.

22 Wannemacher RW, Pekarek RS, Klainer AS. et al. Detection of leukocytic endogenous mediator-like mediator of serum amino acids and zinc depression during various infection illnesses. Infect Immunol 1975; 873-5.

23 Morrison B, Shenkin A, McLelland A. et al. Intraindividual variation in commonly analysed serum constituents. Clin Chem 1979; 25: 1799-805.

24 Solomons NW, Elson CO, Pekarek RS, Jacob RA, Sandstead HH, Rosenberg IH. Leukocytic endogenous mediator in Crohn's disease. Infect Immunol 1978; 22: 637-9.

25 Mills PR, Fell GS. Zinc in inflammatory bowel disease.
Am J Clin Nutr 1979; 32: 2172-3.

26 Sandstead HH. Some trace elements which are essential for human nutrition: zinc, copper, manganese, and chromium. Prog Food Nutr Sci 1975; 1: 371 .

27 Beisel WR. Trace elements in infectious processes. Med Clin North Am 1976; 60: 831-49.

28 van Rij AM, Godfrey PJ, McKenzie JM. Amino acid infusions and urinary zinc excretion. J Surg Res 1979; 26: 293-9.

29 Freeman JB, Stegink LD, Meyer PD, Fry LK, Denbesten L. Excessive urinary zinc losses during parenteral alimentation. J Surg Res 1975; 18: 463-9.

30 Cousins RJ. Regulatory aspects of zinc metabolism in liver and intestine. Nutrit Rev 1979; 37: 97-103. 